\title{
Rapidly fatal respiratory failure and angioimmunoblastic lymphadenopathy: possible contributions of immunoblastic leukaemia, chemotherapy, and multiple antibodies directed against mature blood cells
}

\author{
PM TRENCHARD, * JA WHITTAKER, $\dagger$ J GOUGH, $\ddagger$ H PARRY $† \S$ \\ From the *Welsh Regional Transfusion Centre, Rhydlafar, St Fagans, Cardiff, and the Departments of \\ $\dagger$ Haematology and $\ddagger$ Histopathology, University Hospital of Wales, Heath Park, Cardiff
}

SUMMARY A patient with angioimmunoblastic lymphadenopathy, immunoblastic leukaemia, pulmonary immunoblastic infiltration, and multiple antihaemocytic antibodies in his serum deteriorated rapidly after chemotherapy due to severe progressive respiratory dysfunction. The haematological and immunological changes that accompanied this are described and discussed in the light of the pulmonary changes observed at necropsy of pulmonary oedema, fibrinous thrombi within venules, and immunoblastic infiltration of these thrombi and the venule walls. A pathophysiological mechanism is postulated in an attempt to rationalise these findings, and to act as a guide for the future assessment and management of similar cases.

The major studies of angioimmunoblastic lymphadenopathy (AIL) series incorporating between four and 38 patients ${ }^{1-8}$ have enabled the unique histology of this disease to be clearly defined and have revealed some commonly occurring clinical manifestations, which include progressive lymphadenopathy, rash, fever, autoimmune haemolytic anaemia, and a polyclonal increase of immunoglobulin. The disease can be classfied as a hyperimmune disorder of the B-cell system ${ }^{3469-11}$ perhaps related to a reduction in suppressor T-cell activity. ${ }^{2} 691213$ Levamisoleinduced remissions support the latter concept. ${ }^{1415}$ Others regard the clinical pattern and histological evolution of AIL to be very similar to those of a graft-versus-host reaction. ${ }^{1216}$ Recently, intracytoplasmic virus-like particles have been observed in AIL lymphoid cells. ${ }^{17} 18$

Less common clinical features of AIL may include the presence of numerous immunoblasts in the peripheral blood, 27819 which we define as immunoblastic leukaemia (IBL) if the concentration exceeds $1.0 \times 10^{9} / 1\left(1000 / \mathrm{mm}^{3}\right)$-diffuse interstitial pul-

§Present address: Department of Haematology, Musgrove Park Hospital, Taunton, Somerset.

Accepted for publication 9 October 1980 monary infiltration by immunoblasts, ${ }^{2} 51319-23$ and additional immunological aberrations such as the presence of multiple autoantibodies, ${ }^{10}$ hypocomplementaemia, ${ }^{54-26}$ and cutaneous anergy-all well reviewed by Cullen et al. ${ }^{8}$

We report on a case of AIL exhibiting the special features of IBL, pulmonary infiltration, and some previously undescribed serum antibodies directed against neutrophils, lymphocytes, and platelets. The possible interrelations of these features are discussed in detail, and particularly the immunological changes induced by chemotherapy since these may have contributed significantly to the morbidity and death of the patient. A pathophysiological scheme is suggested both to summarise the findings in this case and also to provide a scheme upon which to base the investigation and management of any cases of AIL showing similar features in the future.

\section{Case report}

A 53-year-old Caucasian steel-worker had been fit throughout his life until he first noticed a lump in his neck-defined as day 1 of the illness. By day 15 he had become anorectic, slightly dyspnoeic with a dry cough, and had lost $3 \mathrm{~kg}$ in weight. Examination show- 
ed enlarged, discrete, painless, rubbery lymph nodes bilaterally in the neck, axillae, and groins $\left(\frac{1}{2}-1 \mathrm{~cm}\right.$ in diameter), and a firm smooth non-tender liver extending $6 \mathrm{~cm}$ below the costal margin. The spleen was impalpable. A plain abdominal $x$-ray examination showed the large liver but was otherwise normal. A maculopapular non-pruritic erythematous rash was on the trunk and arms. Some scattered crepitations were audible at both lung bases, and a chest $x$-ray examination (Fig. 1) showed bilateral hilar lymphadenopathy, with generalised nodular and linear opacities throughout both lung fields, although most prominent at the right base. A significant lymphocytosis was seen in the peripheral blood, but only slight anaemia (Figs 2 and 3), and the blood film cellular morphology appeared normal.

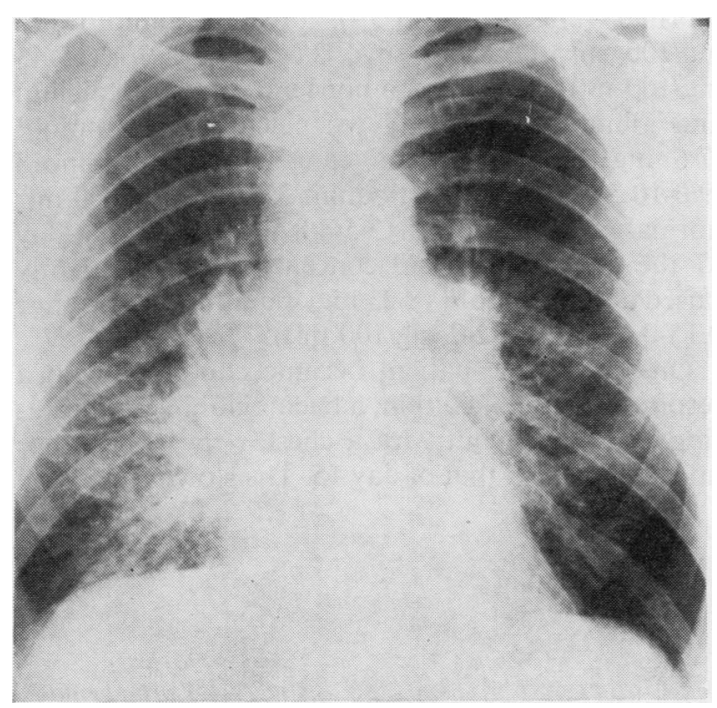

Fig. 1 Chest $\mathrm{x}$-ray film showing bilateral hilar lymphadenopathy and generalised nodular and linear opacities throughout both lung fields in a case of angioimmunoblastic lymphadenopathy with pulmonary immunoblastic infiltration.

On day 22 when the patient was admitted to hospital the lymph nodes had enlarged to a maximum diameter of $2.5 \mathrm{~cm}$, the liver was palpable $8 \mathrm{~cm}$ below the costal margin, and the spleen was just palpable. The rash was unchanged, but in other areas the skin and mucous membranes were pale. A strongly positive direct Coombs test (broad spectrum), a raised concentration of hydroxybutyrate dehydrogenase (HBD) in the serum (650 IU/1; normal range $0-360)$, a low serum haptoglobin concentration $<0.3$ $\mathrm{g} / 1$ (normal range $0 \cdot 3-2.0 \mathrm{~g} / \mathrm{l}$ ) and increased urine urobilinogenall indicated the presence of autoimmune

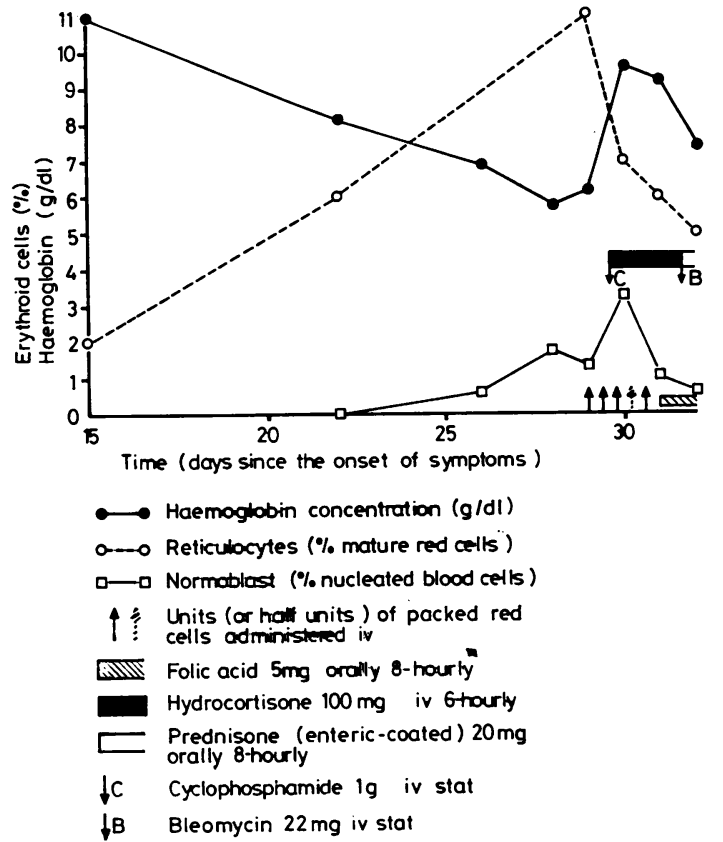

Fig. 2 Peripheral blood erythroid changes accompanying the progression of the disease and the initiation of chemotherapy in a case of angioimmunoblastic lymphadenopathy with multiple circulating antihaemocytic antibodies.
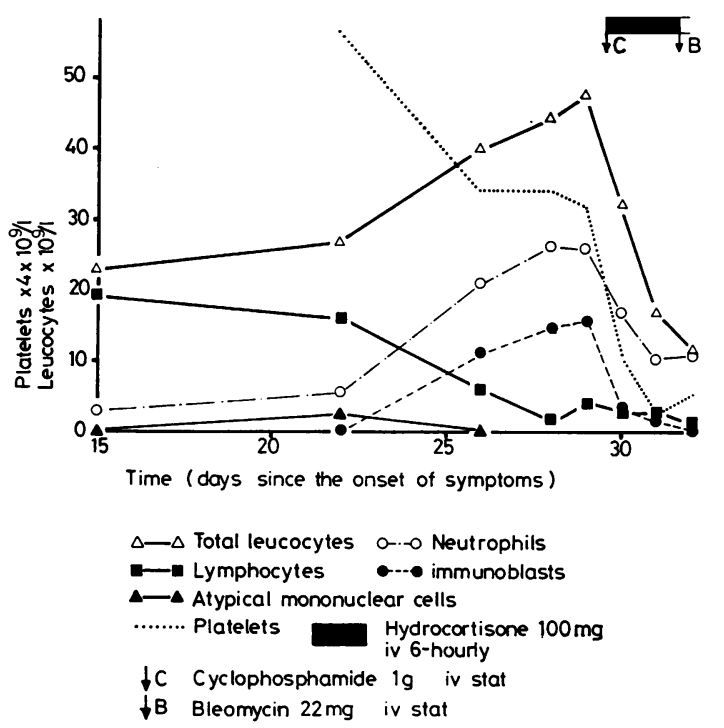

Fig. 3 Peripheral blood leucocyte and platelet changes accompanying the progression of the disease and the initiation of chemotherapy in a case of angioimmunoblastic lymphadenopathy with immunoblastic leukaemia and multiple circulating antihaemocytic antibodies. 
extravascular haemolysis, as did the blood film (cold agglutination, spherocytes, increased polychromasia, absence of fragments) and the other haematological indices (Fig. 2). The patient still complained of the same respiratory symptoms as on day 15 although the signs at the lung bases had disappeared. A repeat full physical examination was normal in all other respects, and in particular he was apyrexial with a regular pulse rate of $90 / \mathrm{min}$, a blood pressure of $130 / 70$, a normal electrocardiogram, and a respiratory rate of $15 / \mathrm{min}$. There was no history of rigors, night sweats, or recent drug intake. The histology of a cervical lymph node biopsied on day 23 showed alteration of the nodal architecture by a diffuse proliferation of small blood vessels, a pleomorphic mononuclear cellular infiltrate composed of immunoblasts, plasma cells, and lymphocytes, and the presence of PAS-positive intercellular material. This well-established histological triad ${ }^{2}$ enabled a definite diagnosis of AIL to be made (agreed by three histologists).

From day 26 the patient deteriorated clinically with increasing respiratory distress and cough, which paralleled the appearance of definite IBL (Fig. 4) and progressive leucoerythroblastic anaemia (Fig. 2). Thick mucoid sputum was obtained on day 27 only, and treatment for a possible chest infection with oral ampicillin/cloxacillin (days 27, 28), septrin (days 31 , 32 ), and salbutamol and intravenous gentamicin/ lincomycin (days 29, 30) were all without clinical benefit, although no bacterial or fungal organism could be cultured from the sputum of day 27 .

A bone marrow aspirate on day 26 was hypocellular but with $25 \%$ immunoblasts, in contrast to an extremely cellular trephine biopsy on day 28 that showed gross infiltration by immunoblasts and a considerable increase in small and medium-sized reticulin fibres, as described by Brearley et al. ${ }^{27}$

Throughout the illness the plasma concentrations is of alkaline phosphatase and asparate aminotrans- $\overrightarrow{0}$ ferase, and sodium, chloride, potassium, and phosphate ions were all normal. In contrast, however, the plasma concentrations of bilirubin, hydroxybutyrate dehydrogenase, and urea rose slowly throughout the study reaching the following concentrations during $\omega$ the last two days of life: bilirubin $30 \mu \mathrm{mol} / 1(1.7 \mathrm{ir}$ $\mathrm{mg} / 100 \mathrm{ml}$; normal range $0-17 \mu \mathrm{mol} / 1(0-1.0 \mathrm{mg} / 100$ $\mathrm{ml})$ ), hydroxybutyrate dehydrogenase $880 \mathrm{IU} / 1$ (normal range 0-360 IU/l), urea $12 \mathrm{mmol} / \mathrm{l}$ (72 $\mathrm{mg} / 100 \mathrm{ml}$; normal range $2 \cdot 5-7 \cdot 5 \mathrm{mmol} / 1$ (15-45 $\mathrm{mg} / 100 \mathrm{ml})$ ). The plasma concentrations of calcium and albumin fell slowly to: calcium $1.90 \mathrm{mmol} / 1$ $(7.6 \mathrm{mg} / 100 \mathrm{ml}$; normal range $2 \cdot 26-2.60 \mathrm{mmol} / \mathrm{l}$ $(9 \cdot 0-10 \cdot 5 \mathrm{mg} / 100 \mathrm{ml}))$, albumin $21 \mathrm{~g} / 1(2 \cdot 1 \mathrm{~g} / 100 \mathrm{ml}$; . normal range $35-48 \mathrm{~g} / 1(3 \cdot 5-4 \cdot 8 \mathrm{~g} / 100 \mathrm{ml}))$. On day 31 the plasma uric acid concentration was slightly raised at $0.49 \mathrm{mmol} / 1(8.23 \mathrm{mg} / 100 \mathrm{ml}$; normal range $0 \cdot 15-0 \cdot 4 \mathrm{mmol} / \mathrm{l}(2-7 \mathrm{mg} / 100 \mathrm{ml}))$.

On day 29 the patient became confused, with a respiratory rate of $40 / \mathrm{min}$, a haemoglobin concentration of $6.2 \mathrm{~g} / \mathrm{dl}$, but with a chest $x$-ray appearance unchanged from that of day 15 . The slow transfusion 西

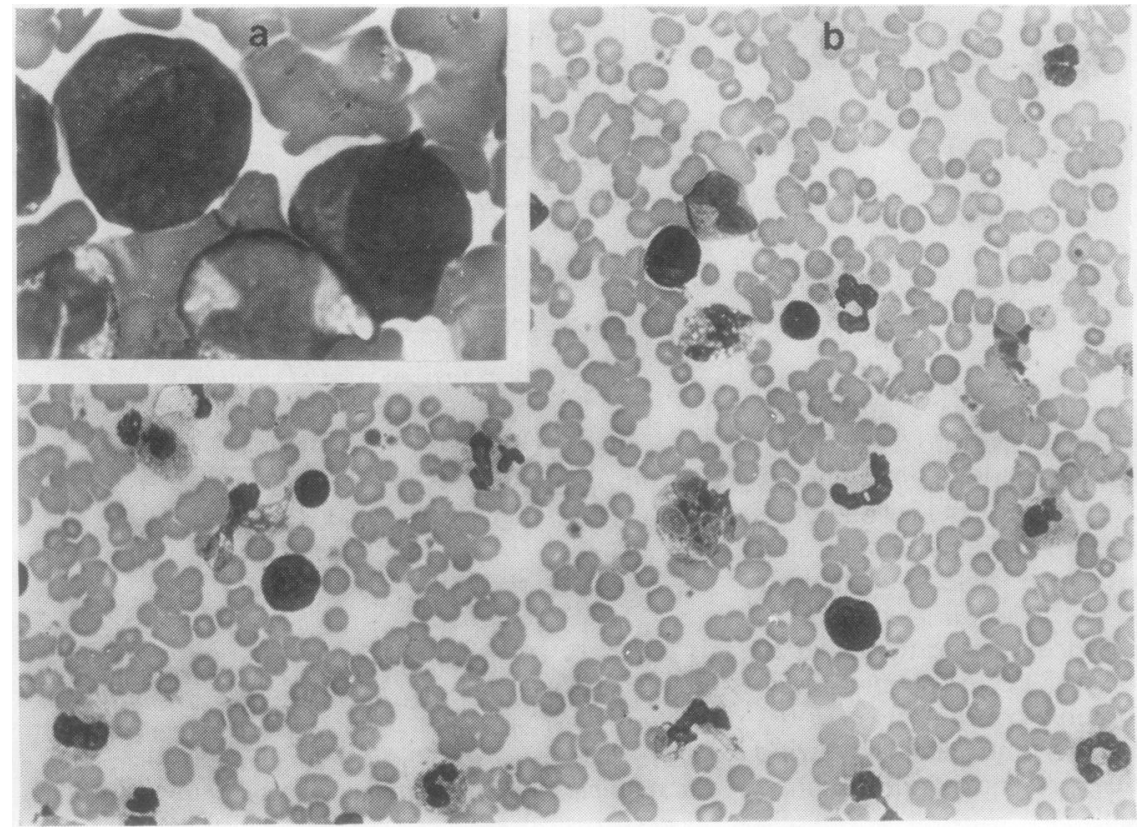

Fig. 4 A pre-chemotherapy buffy coat preparation from the peripheral blood of $a$ case of angioimmunoblastic lymphadenopathy with immunoblastic leukaemia showing (a) two immunoblasts at the edge of the preparation $\times 1800 ;(b)$ the more mature immunoblasts (including lymphoplasmacytoid cells) predominant in the thinner part of the preparation $\times 500$. 
of $4 \frac{1}{2}$ units of packed red cells over 36 hours (Fig. 2) did not, however, alter any of these respiratory symptoms or signs. In an attempt therefore to treat the underlying AIL and IBL, chemotherapy was started using cyclophosphamide, corticosteroids, and bleomycin as shown in Figs 2 and 3. This apparently arrested the leukaemic phase of the disease and was accompanied by a reduction in the concentrations of some other cellular components of the blood (Fig. 3).

The patient, however, continued to deteriorate with abnormal blood gases (pH 7.33, $\mathrm{PcO}_{2} 29 \mathrm{~mm}$ $\mathrm{Hg}(3.8 \mathrm{kPa}), \mathrm{PO}_{2} 50 \mathrm{~mm} \mathrm{Hg}(6.6 \mathrm{kPa})$, standard bicarbonate $17 \mathrm{mmol}(\mathrm{mEq}) / \mathrm{l}$ and base excess$10.0 \mathrm{mmol}(\mathrm{mEq}) / 1$; day 30 ) and increasing confusion, leading to coma and death in respiratory failure on day 32. The low platelet counts before death (days $30,31,32$, Fig. 3 ) could not be readily attributed to disseminated intravascular coagulation since the slight rise of fibrin degradation products within the range of $40-80 \mathrm{mg} / \mathrm{l}$ was accompanied throughout this period by fibrinogen titres $(1 / 64$; normal range $1 / 32-1 / 128$ ), one-stage prothrombin times, kaolincephalin clotting times, and individual assays for factors V, VII, VIII, IX, X, and XII, which were all

Peripheral blood haematological and immunological changes accompanying the progression of the disease and the initiation of chemotherapy in a case of angioimmunoblastic lymphadenopathy with immunoblastic leukaemia, pulmonary immunoblastic infiltration, and multiple circulating antihaemocytic antibodies

\begin{tabular}{|c|c|c|c|c|c|c|c|c|c|c|c|c|c|}
\hline \multirow{3}{*}{\multicolumn{2}{|c|}{ PERIPHERAL BLOOD }} & \multirow{3}{*}{\multicolumn{2}{|c|}{ COMPONENTS }} & \multicolumn{5}{|c|}{$\begin{array}{l}\text { PERIPHERAL BLOOD COMPONENT } \\
\text { VALUES ON DAYS INDICATED }\end{array}$} & \multirow{2}{*}{\multicolumn{4}{|c|}{$\begin{array}{l}\text { DIRECTION OF CHANGE } \\
\text { ( } \downarrow \text { OR } \uparrow \text { ) AND RATE OF } \\
\text { CHANGE (A OR B; amOUnt } \\
\text { Per daY) OF COMPONENT } \\
\text { VALUES }\end{array}$}} & \multirow{5}{*}{$\begin{array}{c}\text { RATIO } \\
\text { OF } \\
\text { B } / \text { A }\end{array}$} \\
\hline & & & & \multirow{2}{*}{\multicolumn{2}{|c|}{$\begin{array}{l}\text { PRE-CHEMO- } \\
\text { THERAPY }\end{array}$}} & \multirow{2}{*}{\multicolumn{3}{|c|}{$\begin{array}{l}\text { POST-CHEMO- } \\
\text { THERAPY }\end{array}$}} & & & & & \\
\hline & & & & & & & & & \multirow{2}{*}{\multicolumn{2}{|c|}{$\begin{array}{l}\text { PRE-CHEMO- } \\
\text { THERAPY }\end{array}$}} & \multirow{2}{*}{\multicolumn{2}{|c|}{$\begin{array}{l}\text { POST-CHEMO- } \\
\text { THERAPY }\end{array}$}} & \\
\hline \multirow{2}{*}{\multicolumn{2}{|c|}{ TYPE }} & \multirow[t]{2}{*}{ UNI TS } & \multirow{2}{*}{$\begin{array}{l}\text { NORMAL } \\
\text { RANGE }\end{array}$} & DAY & DAY & DAY & DAY & DAY & & & & & \\
\hline & & & & 22 & 29 & 30 & 31 & 32 & $4 / t$ & A & $4 / t$ & B & \\
\hline \multicolumn{2}{|c|}{ IMMUNOBLASTS } & $\times 10^{9} .1^{-1}$ & & 2.7 & 15.6 & 3.1 & 1.7 & 0.0 & 4 & 1.9 & $\downarrow$ & 7.0 & $\mathbf{R}$ \\
\hline \multicolumn{2}{|c|}{ LYMPHOCYTES } & $\times 10^{9} .1^{-1}$ & $1.5-4.0$ & 16.0 & 4.3 & 2.7 & 2.8 & 1.1 & $\downarrow$ & 1.7 & $\downarrow$ & 1.0 & 0.6 \\
\hline \multirow{4}{*}{ 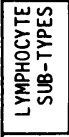 } & T-CELLS & $\%$ & $21-79$ & & & 37 & \multicolumn{7}{|c|}{$E$ - rosettes } \\
\hline & (B-CELLS) & $\%$ & $2-23$ & & & 21 & \multicolumn{7}{|c|}{ EAC - rosettes } \\
\hline & $B$-CELLS & $\%$ & $4-40$ & & & 48 & \multicolumn{7}{|c|}{ immunofluorescent surface immunoglobul in } \\
\hline & NULL CELLS & $\%$ & $7-56$ & & & 15 & & & & & & & \\
\hline \multirow{2}{*}{\multicolumn{2}{|c|}{$\begin{array}{l}\text { IMMUNOGLOBULIN G } \\
\text { IMMYUNOGLOBULIN A }\end{array}$}} & g. $1^{-1}$ & $5.0-16.0$ & 20.0 & 26.4 & 39.0 & & & $\mathbf{T}$ & 0.71 & 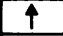 & 12.6 & 17.6 \\
\hline & & $9.1^{-1}$ & $1.25-4.25$ & 4.0 & 5.0 & 7.2 & & & 4 & 0.11 & $\mathbf{T}$ & 2.2 & 20.0 \\
\hline \multicolumn{2}{|c|}{ IMMUNOGLOBULIN M } & $9.1^{-1}$ & $0.47-1.70$ & 7.5 & 13.3 & 15.0 & & & 4 & 0.64 & $\dot{\varphi}$ & 1.7 & 2.7 \\
\hline \multirow{6}{*}{ 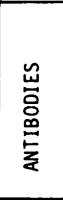 } & RED CELL* & $4^{\circ} \mathrm{C}$ titre & & & & $1 / 2048$ & \multicolumn{7}{|c|}{ anti-I (reduced to $1 / 256$ at RT) } \\
\hline & LYMPHOCYTE & $\%$ & & & & 93 & \multicolumn{7}{|c|}{ cell kill/80-cell panel/NSA } \\
\hline & NEUTROPHIL & $\%$ & & & & 40 & \multicolumn{7}{|c|}{ agglutination/60-cell panel/NSA } \\
\hline & PLATELET & titre & & & & $1 / 40$ & \multicolumn{7}{|c|}{ complement fixation } \\
\hline & PLATELET & titre & & & & $1 / 16$ & \multicolumn{7}{|c|}{ agglutination } \\
\hline & OTHER + & & & & & ND & & & & & & & \\
\hline \multicolumn{2}{|c|}{ HAEMOGLOBIN } & g.dl & $13.0-18.0$ & 8.1 & $(5.8)$ & 9.6 & & 7.4 & $\downarrow$ & 0.4 & $\downarrow$ & 1.1 & 2.9 \\
\hline \multicolumn{2}{|c|}{ NEUTROPHILS } & $\times 10^{9} .1^{-1}$ & $2.0-7.5$ & 5.3 & 25.5 & 16.6 & 10.1 & 10.5 & $\uparrow$ & 2.9 & $t$ & 7.7 & $R$ \\
\hline \multicolumn{2}{|c|}{ PLATELETS } & $\times 10^{9} .1^{-1}$ & $150-400$ & 255 & 125 & 40 & 9 & 19 & $\downarrow$ & 18.6 & $\downarrow$ & 58.0 & 3.1 \\
\hline$\sum_{u} \cong$ & C3 & $\mathrm{mg} .1^{-1}$ & $700-1600$ & & & 165 & & & & & & & \\
\hline 崖 & $C 3 c / C 3 d$ & & & & & ND & immun & oelect & rophere & es is & & & \\
\hline 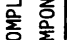 & $\mathrm{C4}$ & $\mathrm{mg} .1^{-1}$ & $130-500$ & & & 25 & & & & & & & \\
\hline 8 농 & $c 4 a$ & & & & & ND & immur & oelect & rophere & es is & & & \\
\hline
\end{tabular}

$\mathbf{R}=$ Reversed direction of change of component values before and after chemotherapy.

Longest horizontal boxes contain a brief indication of the corresponding methods used.

$\star$ Pan-reacting antibody also detected at $37^{\circ} \mathrm{C}$ in saline, albumin, and by indirect Coombs; it was not possible to elucidate whether this represented the established anti-I with a high thermal amplitude, or an additional antibody (or antibodies).

+Other antibodies directed against nucleus, smooth muscle, mitochondria, parietal cells, thyroid, lung, salivary gland, brucella, influenza, parainfluenza, psittacosis/lymphogranuloma venereum, rickettsia, respiratory syncytial virus, mycoplasma, mumps, and herpes simplex were all tested for but not detected (ND). The Paul-Bunnell test was also negative.

NSA = No specificity assignable.

$(5 \cdot 8)=$ Data from day 28 , not day 29

Corresponding references describe the methods used for the quantitative or semiquantitative measurement of (i) immunoglobulin classes, ${ }^{28}$ (ii) lymphocytotoxic antibodies, ${ }^{29}$ (iii) neutrophil agglutinins, ${ }^{30}$ (iv) complement fixing antiplatelet antibodies, ${ }^{31}$ (v) platelet agglutinins. ${ }^{32}$ 
entirely normal.

The immunological changes during this patient's illness and their relation to the cellular changes in the blood are of particular interest and are given in the Table, with the technical methods used.

At necropsy the reticuloendothelial system showed marked infiltration by AIL at all the sites examinedcervical, mesenteric, para-aortic, splenic and mediastinal lymph nodes, spleen, bone marrow, and the portal tracts of the liver. The degree of infiltration was considerably less than that seen in the original lymph node biopsy specimen, and there were focal areas of cellular depletion. The upper dermis at the site of the rash showed a similar infiltrate.

Both lungs were firm and heavy (left $1020 \mathrm{~g}$, right $960 \mathrm{~g}$ ), deep pink on section, and the main bronchi contained a small amount of mucoid material. Microscopically there was severe generalised oedema of both lungs affecting all lobes. A number of small bronchi were obstructed by mucus and although there was some degree of bronchopneumonia in terms of alveolar polymorphic inflammatory exudate this was limited to peribronchial areas of a few airways. A lymphoid infiltrate, which included many plasmacytoid cells, was seen particularly in relation to small bronchi and venules, with very little extension into alveolar walls and alveoli. The walls of some venules were affected by the infiltrate and fibrinous thrombi were often seen. These showed variable degrees of organisation and were themselves sometimes infiltrated by pleomorphic lymphoid cells. Culture of lung tissue showed a scanty growth of Escherichia coli only, which was regarded as a postmortem contaminant; the patient had been treated with antibiotics so any pathogen may not have grown. Viral culture was negative and there was no histological evidence of fungal infection.

A few petechiae were present on the small bowel mucosa and on the subcapular surfaces of the kidneys. Stress changes were seen in the adrenal gland with a few focal medullary lymphoid infiltrates. The heart, thyroid, pituitary, pancreas, testes, and brain were normal and also the remainder of the alimentary and renal tracts.

\section{Discussion}

Respiratory death in AIL is usually the result of either pulmonary immunoblastic infiltration (PII) ${ }^{23}$ or opportunistic pulmonary infection, ${ }^{2} 8$ or a combination of the two. ${ }^{21} 22$ In the case reported here, however, infection was not found but rather some pulmonary vascular abnormalities that have not previously been described and which may have been secondary, in part at least, to certain immunological abnormalities also peculiar to this patient. The immediate cause of death in this case of AIL waso pulmonary oedema, associated with extensive PII predominantly of the peribronchial tissue, but to aç lesser extent of the walls of many pulmonary venuleso and the fibrinous thrombi occluding some of them.흐

Others have observed PII in this disease, some $\frac{\overline{\bar{\alpha}}}{\bar{T}}$ having relied upon clinical and radiological findings $\widetilde{\otimes}$ alone, ${ }^{13} 19$ others having obtained definite histologicalo confirmation of immunoblastic infiltration: focal, ${ }^{2^{\infty}}$ diffuse perivascular, ${ }^{5}$ diffuse interstitial, 8202223. diffuse interstitial infiltration associated with infiltra- $\overrightarrow{\vec{\omega}}$ tion and destruction of the walls of small bronchi. ${ }^{21} \omega$ This report, however, gives the first description of pulmonary venule infiltration and occlusion in AIL. It is not possible for the PII in this case to have arisen $+{ }_{i r}^{+}$ by the haematogenous spread of immunoblasts, + since the pulmonary lesions were well establishedo before IBL appeared (Figs 1 and 3). This agrees with을 other descriptions of AIL associated with eitherIBL 7819 or PII, $2581319-23$ and none of these 3 studies shows an obvious association between IBL and PII in AIL. The lymphocytosis observed at $\vec{c}$ presentation, however, should not be ignored since it $\stackrel{\infty}{-}$ is possible that lymphocytes of normal morphology by light microscopy, and perhaps even at normalo blood concentrations, are responsible for the haematogenous spread of the disease with furthero differentiation into immunoblasts occurring at the $\frac{\circ}{\triangleright}$ metastatic site. The future assessment of this possi- $\cong$ bility will require at least the sequential monitoring of the concentrations of the various lymphocyte 3 subpopulations in the blood, throughout the initial, intermediate, and terminal phases of this disease, particularly since associated abnormalities of the B-cell system 34691011 and the T-cellosystem $^{6}{ }^{912-1520}$ have been described. The B-cell and 3 . T-cell values obtained in this patient on day 30 , were $\delta$ not particularly abnormal, but this further emphasises the need for sequential studies. Nevertheless, 음 it is of particular interest that the patient's respiratory symptoms deteriorated coincidentally with the appearance of IBL and it suggests that the latter may have resulted in the haematogenous dissemina- $\Omega$ tion of immunoblasts to lungs already infiltrated by $N$ AIL thereby aggravating the severity of the local N pathology and likewise the symptomatology. It is conceivable that this mechanism was primarily ${ }_{6}$ responsible for the vascular infiltration already $\frac{\odot}{\Phi}$ discussed with fibrin deposition and thrombus $\stackrel{?}{+}$ infiltration occurring secondarily, although other $\square$ possible immunoblast migration routes are indicated in Fig. 5.

As in many cases of the disease red cell auto- $\frac{\vec{\Phi}}{0}$ antibodies were present and were responsible for severe haemolytic anaemia (Figs 2 and 3, Table). Many additional autoantibodies that have also beeno 
described in this disease (Table 6 of Cullen MH et al. $)^{8}$ were tested for in this case but yielded negative results (Table). Additional studies, however, showed the presence of multiple antihaemocytic antibodies in the serum directed against lymphocytes, platelets, and neutrophils. This is the first description of such a finding, apart from an isolated report of "an apparent lympholytic factor" in the serum of one other case. ${ }^{3}$ It was not possible to study the specific immunoglobulin classes carrying these separate antihaemocytic activities, nor was it possible to study them by elution from the patients own white cells and platelets, so it is only by inference that they are referred to as autoantibodies.

The neutrophil and platelet antibodies were detected by agglutination without the addition of complement and such agglutination occurring in vivo would lead to trapping of some of the neutrophil and platelet aggregates within the pulmonary vasculature, since the lungs form part of the reticuloendothelial system. This could reduce vessel/airway gaseous exchange in the lungs and also predispose to local pulmonary intravascular coagulation causing further reduction in gaseous exchange. It is postulated therefore, that the presence of multiple circulating antihaemocytic antibodies might aggravate defects in pulmonary function in AIL by this mechanism, which is completely separate to that of PII. The impairment of gaseous exchange in the latter would be a direct effect of immunoblastic infiltration of the pulmonary interstitium or walls of small pulmonary vessels, or both. Both fibrin occlusion of pulmonary venules and PII would be expected to predispose to pulmonary oedema due to a combination of vascular occlusion and inflammation. Any inflammatory process due to PII will itself predispose to local intravascular coagulation, and any agglutinating antibodies to neutrophils or platelets, or both, whether released from immunoblasts in the vessel wall or in the interstitium (multiple antihaemocytic antibodies in the tissues) could cross the vessel walls and direct their effects intravascularly, thereby enhancing any local accumulation of neutrophils, platelets, and fibrin. These postulated pathophysiological mechanisms are summarised in Fig. 5 and are in complete agreement with the necropsy findings.

The progressive respiratory dysfunction in this patient was, however, accelerated by chemotherapy, which was itself accompanied by very large increases in the serum concentrations of IgG and IgA (approximately $50 \%$ absolute increase; approximately $2000 \%$ increase in the rate of increase) relative to the values before chemotherapy (Table). It may be postulated, therefore, that rapid chemotherapeutic destruction of immunoblasts caused the release of preformed intracellular immunoglobulins into the serum, thereby accounting for this rapid rise in immunoglobulin concentrations. A parallel increase in antihaemocytic antibodies in both the serum and tissues could also be expected if one assumes that these antibodies are produced by the pathological immunoblast population. Any inflammatory effects of PII would be similarly aggravated during such a period of immunoblast destruction. The net result of chemotherapy would therefore be the amplification of the pathophysiological mechanisms already postulated above and in Fig. 5, leading to a rapid deterioration in pulmonary function.

The smaller increase in IgM after chemotherapy (approximately 10\% absolute increase; approximately $300 \%$ increase in the rate of increase) relative to the IgG and IgA changes (Table) may be explained by transfusion if it is assumed that much of the serum IgM was composed of the anti-I red cell autoantibody known to be of high titre in this case (Table). Any red cell transfusion would therefore tend to obscure a rising serum IgM concentration, as a result of $\operatorname{IgM}$ adsorption on to the transfused red cells.

The rate of fall of the peripheral blood lymphocyte concentration slowed progressively from day 22 until death, despite the presence of complementdependent lymphocytotoxic antibodies in the serum, and despite chemotherapy. The serum complement concentrations, however, had reached very low levels by day 30 (Table), and it may be argued that any modification of peripheral blood lymphocyte concentrations by complement-dependent lymphocytotoxic antibodies would be minimised by the low availability of complement. Similarly, any rise in lymphocytotoxic antibodies after chemotherapy, as postulated for the antihaemocytic antibodies above, would exert a minimal cytotoxic effect. Hypocomplementaemia has been described in other cases of AIL, ${ }^{54-26}$ but the findings in this case suggest that lymphocytotoxic antibodies may directly reduce the blood lymphocyte concentration and consume complement in the process so that the resultant low complement concentrations would abrogate further lymphocytotoxic effects. This emphasises the need for serial monitoring in such cases, not only of the total peripheral blood lymphocyte concentrations, but also of the concentrations of different lymphocyte subpopulations, complement levels, and the presence or absence of immune complexes. Unfortunately it was not possible to screen for the latter in this case.

The only haemopoietic cell line that provides evidence for chemotherapy exerting very little effect on normal haemopoiesis in this patient during the short post-chemotherapy period (days $30,31,32$ ) is that of erythropoiesis. The two linear but inversely related trends of haemoglobin concentration against 
time and reticulocyte percentage against time-as seen between days 15 and 29 in Fig. 2-indicate the pre-chemotherapy level of erythropoiesis in terms of

the reticulocyte responses at various haemoglobin concentrations. These were used to predict the reticulocyte counts for the post-chemotherapy
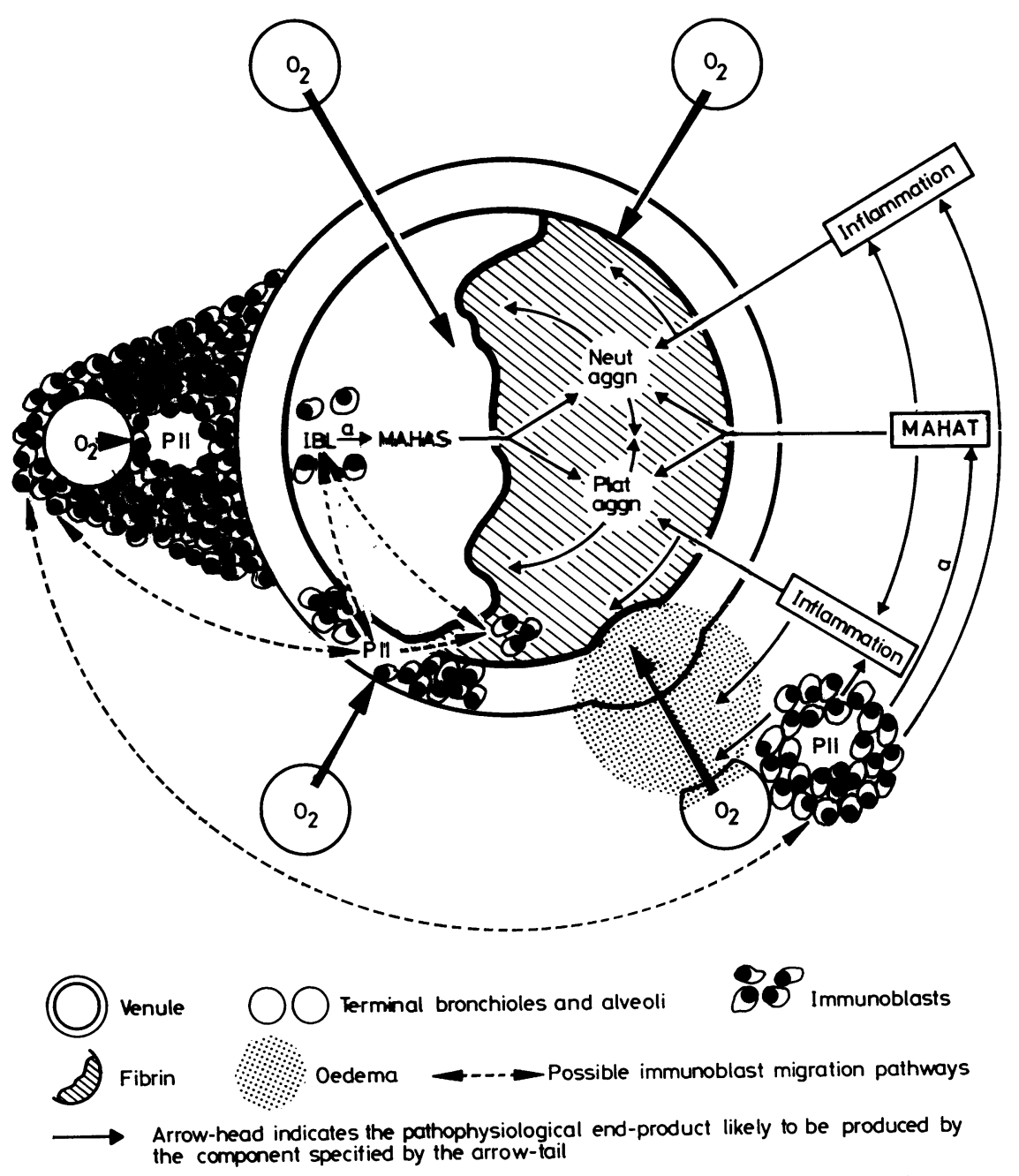

IBL Immunoblast leukaemia MAHA T/S Multiple anti-haemocytic antibodies in the tissue/ serum

PII Pulmonary immunoblastic infiltration Neut aggn Neutrophil agglutination

Plat aggn Platelet agglutination a Principle chemotherapeutic amplification sites

Perivascular components that may be able to produce small vessel intravascular effects transmurally as indicated

Extent to which interstitial oxygen $\left(\mathrm{O}_{2}\right)$ diffusion may occur from the airways to the blood, with possible blockages indicated at the arrow-tips

Fig. 5 Pathophysiological mechanisms that may result in various pulmonary defects in patients with angioimmunoblastic lymphadenopathy, pulmonary immunoblastic infiltration and multiple antihaemocytic antibodies in the serum, and the possible amplification of some of these by chemotherapy. 
haemoglobin concentrations of days 30,31 , and 32 and gave values of $3 \%, 3.5 \%$, and $7.5 \%$ respectively. The mean predicted reticulocyte count after chemotherapy of $4.7 \%$ is slightly less than the mean observed reticulocyte count of $6 \%$ (incorporating the separate counts of $7 \%, 6 \%$, and $5 \%$ for days 30 , 31 , and 32 respectively) and suggests that the erythropoietic levels before and after chemotherapy are very similar. This implies that the threefold increase in the rate of fall in haemoglobin concentration after chemotherapy (Table) is due to a dramatic increase in the rate of haemolysis rather than to a marked decrease in the rate of erythropoiesis, and would therefore support the hypothesis that the chemotherapy primarily destroys immunoblasts and releases preformed antibodies with specific antihaemocyte activity.

Unfortunately these hypotheses can only be tentative, particularly since it is impossible to be certain that haemopoiesis was relatively unaffected by the cyclophosphamide. Although Cullen et al. ${ }^{8}$ advise against the use of corticosteroids alone in the treatment of AIL, it may nevertheless be the best initial treatment when the disease is associated with PII, IBL, and multiple circulating antihaemocytic antibodies, since patients could be monitored throughout, in the definite absence of any myelosuppression induced by chemotherapy. Frequent serial immunological, haematological, and pulmonary studies, if performed before and during such treatment, would more readily allow the hypotheses above to be verified or refuted. This would give a much clearer indication of the special dangers of managing patients with AIL who have the associated problems of PII, IBL, and multiple circulating antihaemocytic antibodies.

\section{References}

${ }^{1}$ Frizzera G, Moran EM, Rappaport H. Angio-immunoblastic lymphadenopathy with dysproteinaemia. Lancet 1974;i:1070-3.

2 Frizzera G, Moran EM, Rappaport H. Angio-immunoblastic lymphadenopathy: diagnosis and clinical course. Am J Med 1975;59:803-18.

${ }^{3}$ Lukes RJ, Tindle BH. Immunoblastic lymphadenopathy: a hyperimmune entity resembling Hodgkin's disease. $N$ Engl J Med 1975;292:1-12.

${ }^{4}$ Moore SB, Harrison EG, Weiland LH. Angio-immunoblastic lymphadenopathy. Mayo Clin Proc 1976;51:27380.

${ }^{5}$ Weisenburger D, Armitage J, Dick F. Immunoblastic lymphadenopathy with pulmonary infiltrates, hypocomplementemia and vasculitis: a hyperimmune syndrome. Am J Med 1977;63:849-54.

- Neiman RS, Dervan P, Haudenschild C, Jaffe R. Angioimmunoblastic lymphadenopathy: an ultrastructural and immunologic study with review of the literature. Cancer 1978;41:507-18.

' Pangalis GA, Moran EM, Rappaport H. Blood and bone marrow findings in angio-immunoblastic lymphadeno- pathy. Blood 1978;51:71-83.

${ }^{8}$ Cullen MH, Stansfield AG, Oliver RTD, Lister TA, Malpas JS. Angio-immunoblastic lymphadenopathy: report of ten cases and review of the literature. $Q J \mathrm{Med}$ 1979;48:151-77.

9 Palutke M, Khilanani $\mathbf{P}$, Weise $\mathbf{R}$. Immunologic and electron-microscopic characteristics of a case of immunoblastic lymphadenopathy. Am J Clin Pathol 1976; 65:929-41.

${ }^{10}$ Kreisler JM, Moreno E, Moneo I, et al. Immunological findings in immunoblastic lymphadenopathy: a detailed case study. Clin Exp Immnol 1977;27:497-501.

${ }^{11}$ Schulman P, Budman DR, Vinciguerra VP, Degnan TJ. B-cell activation in angio-immunoblastic lymphadenopathy after immunisation with multivalent pneumococcal polysaccharide vaccine. Lancet 1979;ii:1141.

12 Howarth CB, Bird CC. Immunoblastic sarcoma arising in child with immunoblastic lymphadenopathy. Lancet 1976 ;ii:747-8.

${ }^{13}$ Katsuki A, Shimazaki C, Nakanishi S, et al. A case of immunoblastic lymphadenopathy with repeated interstitial pneumonitis. Rinsho Ketsueki 1979;20:292-300.

${ }^{14}$ Bensa J-C, Faure J, Martin H, Sotto J-J, Schaerer R. Levamisole in angio-immunoblastic lymphadenopathy. Lancet 1976; i:1081.

${ }^{15}$ Ellegaard J, Boeson AM. Restoration of defective cellular immunity by levamisole in a patient with immunoblastic lymphadenopathy. Scand J Haematol 1976;17:36-43.

${ }^{16}$ Gleichmann E, van Elven F, Gleichmann H. Immunoblastic lymphadenopathy, systemic lupus erythematosus, and related disorders: possible pathogenetic pathways. Am J Clin Pathol 1979;72:708-23.

${ }^{17}$ Shamoto M, Suchi T. Intracytoplasmic type-A virus-like particles in angio-immunoblastic lymphadenopathy. Cancer 1979;44:1641-3.

${ }^{18}$ Krueger GR, Bergholz M, Bartsch HH, Fischer R, Schauer A. Rubella virus antigen in lymphocytes of patients with angio-immunoblastic lymphadenopathy. J Cancer Res Clin Oncol 1979;95:87-91.

19 Myers TJ, Cole SR, Pastuszak WT. Angio-immunoblastic lymphadenopathy: pleuro-pulmonary disease. Cancer 1978;40:266-71.

${ }^{20}$ Iseman MD, Schwarz MI, Stanford RE. Interstitial pneumonia in angio-immunoblastic lymphadenopathy with dysproteinaemia: a case report with special histopathologic studies. Ann Intern Med 1976;85:752-5.

${ }^{21}$ Zylak CJ, Banerjee R, Galbraith PA, McCarthy DS. Lung involvement in angio-immunoblastic lymphadenopathy. Radiology 1976;121:513-9.

${ }^{22}$ Asher R, Burgher LW, Feagler JR. Immunoblastic lymphadenopathy presenting as pulmonary interstitial fibrosis. JAMA 1977;237:2411-2.

${ }^{23}$ Spector JI, Miller S. Immunoblastic lymphadenopathy: a report of two cases. JAMA 1977;238:1263-5.

${ }^{24}$ Schultz DR, Yunis AA. Immunoblastic lymphadenopathy with mixed cryoglobulinemia: a detailed case study. $N$ Engl J Med 1975;292:8-12.

${ }^{25}$ Pruzanski W, Sutton DMC, Pantolony D. Angio-immunoblastic lymphadenopathy: an immunochemical study. Clin Immunol Immunopathol 1976;6:62-76.

${ }^{26}$ Cooperberg AA, De Champlain MB, Siminovitch J, Rosenberg A, Schwartz JP. Immunoblastic lymphadenopathy: case report and literature review. Can Med Assoc J 1977;117:53-7.

27 Brearley RL, Chapman J, Cullen MH, Horton MA, Stansfield AG, Waters AH. Haematological features of angio-immunoblastic lymphadenopathy with dysproteinaemia. J Clin Pathol 1979;32:356-60.

${ }^{28}$ Fahey JL, McKelvey EM. Quantitative determination of serum immunoglobulins in antibody-agar plates. $J$ 
Immunol 1965;94:84-90.

29 Terasaki PI, McClelland JD. Microdroplet assay of human serum cytotoxins. Nature 1964 ;204:998-1000.

${ }^{30}$ Lawler SD. Leucoagglutination and cytotoxic tests in leucocyte typing: micro-agglutination technique. In: Elves MW, Nisbet NW. Proceedings of the symposium on transplantation antigens and tissue typing. Oswestry: Robert Jones and Agnes Hunt Orthopaedic Hospital Management Committee, 1969: appendix, 223.
31 Aster RH, Cooper HE, Singer DL. Simplified complement fixation test for the detection of platelet antibodies in . human serum. J Lab Clin Med 1964;63:161-72.

${ }^{32}$ Dausset J, Colin M, Colombani J. Immune platelet $\stackrel{\vec{S}}{+}$ isoantibodies. Vox Sang 1960;5:4-31.

Requests for reprints to: Dr PM Trenchard, Deputy Medical Director, Welsh Regional Transfusion Centre, Rhydlafar, St Fagans, Cardiff CF5 6XF, Wales. 